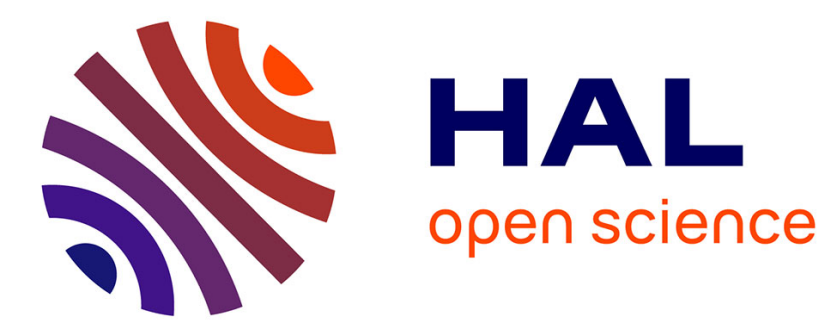

\title{
Benzosultam Synthesis by Gold(I)-Catalyzed Ammonium Formation/Nucleophilic Substitution
}

Romain Pertschi, Jean-Marc Weibel, Patrick Pale, Aurelien Blanc

\section{To cite this version:}

Romain Pertschi, Jean-Marc Weibel, Patrick Pale, Aurelien Blanc. Benzosultam Synthesis by Gold(I)Catalyzed Ammonium Formation/Nucleophilic Substitution. Organic Letters, 2019, 21 (14), pp.56165620. 10.1021/acs.orglett.9b01962 . hal-02347074

\section{HAL Id: hal-02347074 \\ https://hal.science/hal-02347074}

Submitted on 5 Nov 2019

HAL is a multi-disciplinary open access archive for the deposit and dissemination of scientific research documents, whether they are published or not. The documents may come from teaching and research institutions in France or abroad, or from public or private research centers.
L'archive ouverte pluridisciplinaire HAL, est destinée au dépôt et à la diffusion de documents scientifiques de niveau recherche, publiés ou non, émanant des établissements d'enseignement et de recherche français ou étrangers, des laboratoires publics ou privés. 


\title{
Benzosultam Synthesis by Gold(I)-Catalyzed Ammonium For- mation/Nucleophilic Substitution
}

\author{
Romain Pertschi, Jean-Marc Weibel, Patrick Pale, and Aurélien Blanc* \\ Laboratoire de Synthèse, Réactivité Organiques et Catalyse, Institut de Chimie, UMR 7177 - CNRS, Université de Stras- \\ bourg, 4 rue Blaise Pascal, 67070 Strasbourg, France.
}

Supporting Information Placeholder

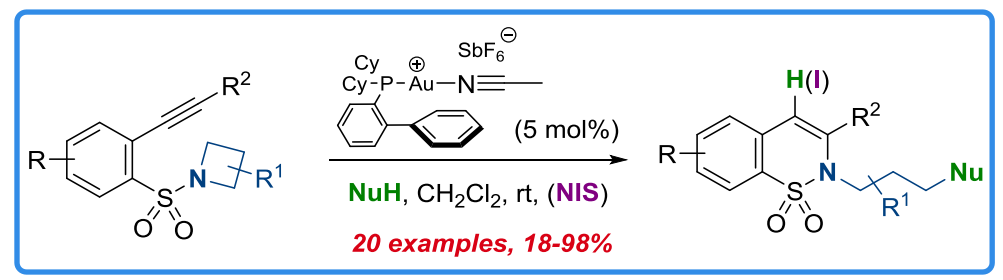

\begin{abstract}
The synthesis of benzosultams has been achieved through a gold(I)-catalyzed ammonium formation strategy. Starting from easily available $N$-(2-alkynyl)phenylsulfonyl azetidine derivatives, a cyclization reaction generated a spiroammonium gold intermediate which was ring-opened by nucleophilic alcohol or indole. This new methodology is compatible with large variation on the substrates and nucleophiles, and allowed to form benzosultams in high yield (18-98\%, 20 examples). This strategy also allowed the preparation of benzosultam analogs via iododeauration and subsequent cross-coupling reactions.
\end{abstract}

Sulfonamides are among the first antibiotics developed from non-natural sources (sulfamides; sulfanilamide and prontosil as prodrug of the former, the 1st ever known, in Figure 1), and some are still in use nowadays (e.g. sulfamethazole, sulfadiazine in Figure 1). Their cyclic analogs named sultams have also been screened for their biological properties, and they exhibit a large variety of activities, such as antiviral, antimicrobial, antiparasitic, anticancer, antidiabetic and antiinflammatory activities. Among them, benzosultams represent an important subclass with broad biological activities. ${ }^{2}$ Some are currently used as drugs to treat hypertension (brinzolamide), ${ }^{3}$ as endothelin receptor antagonist (CI-1034) ${ }^{4}$ or as non-steroidal anti-inflammatory drugs (the oxicam family, such as piroxicam $)^{5}$. Beside these important therapeutic applications, sultams also contributed to the development of stereo- and enantioselective synthesis. ${ }^{6}$

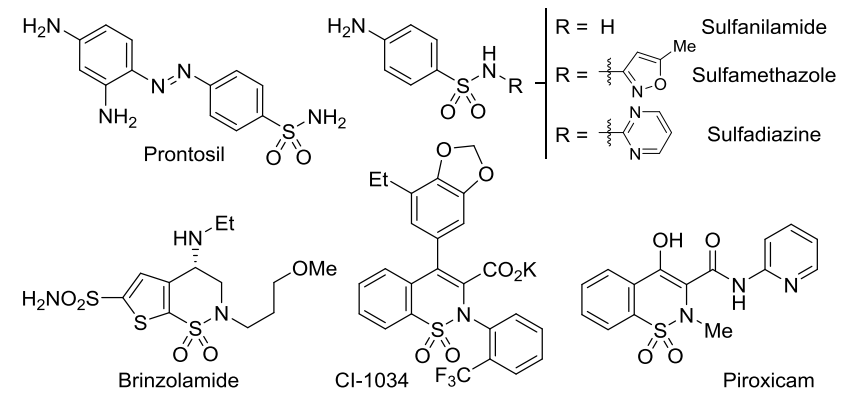

Figure 1. Representative sulfamides and sultams of therapeutic interest.

With such high interest, numerous methods have been developed to access sultams. ${ }^{7}$ As most applications belong to medicinal area, these methods are often driven towards diversity-oriented approaches. Nevertheless, mild, simple, and efficient methods allowing to reach benzosultams with the largest diversity are still highly sought after.

To reach such goals, various metal-catalyzed cyclization processes have been more recently explored, mostly involving $\mathrm{C}-\mathrm{H}$ activation, electrophilic cyclization and ring-closing metathesis. Surprisingly, benzozultam syntheses involving alkynes or azetidines functions seem to have been less investigated. Classical amination of alkynes was applied to the synthesis of benzosultams with silver or copper salts as catalyst (Eq 1 in Scheme 1). ${ }^{8,9}$ Cooperative ruthenium/gold photoredox catalysis has been applied to the preparation of 3,4diarylbenzosultams from 2 (trimethylsilylethynyl)benzenesulfonamides in the presence of aryldiazonium salts (Eq. 2 in Scheme 1). ${ }^{10}$ Benzosultams were accessible by rhodium-catalyzed ${ }^{-}$oxidative $\mathrm{C}-\mathrm{H}$ activation of acylated sulfonamides and subsequent addition of internal alkynes (Eq. 3 in Scheme 1). ${ }^{11}$ Rhodium also catalyzed the rearrangement reaction of chiral $\mathrm{N}$-arenesulfonyl azetidin-3ols into benzosultams via a $\mathrm{C}-\mathrm{C}$ bond cleavage by $\beta$-carbon elimination (Eq. 4 in Scheme 1). ${ }^{12}$ However, no synthetic methods of sultams only based on gold catalysis ${ }^{13}$ have been reported to date. 
In this context, we reasoned that our recently disclosed gold-catalyzed ammonium formation-based cascade reactions ${ }^{14}$ would offer a new and interesting route towards benzosultams 2. Applied to $N$-(2-alkynyl)aryl sulfonyl azetidines $\mathbf{1}$, such reaction would produce a spiroammonium intermediate $\mathbf{A}$, which should then be opened by external protic nucleophiles, while allowing protodemetalation (Scheme 1, bottom).

Scheme 1. Known routes to benzosultams through alkyne cyclization or azetidine ring-opening, and the newly proposed gold-catalyzed synthesis.

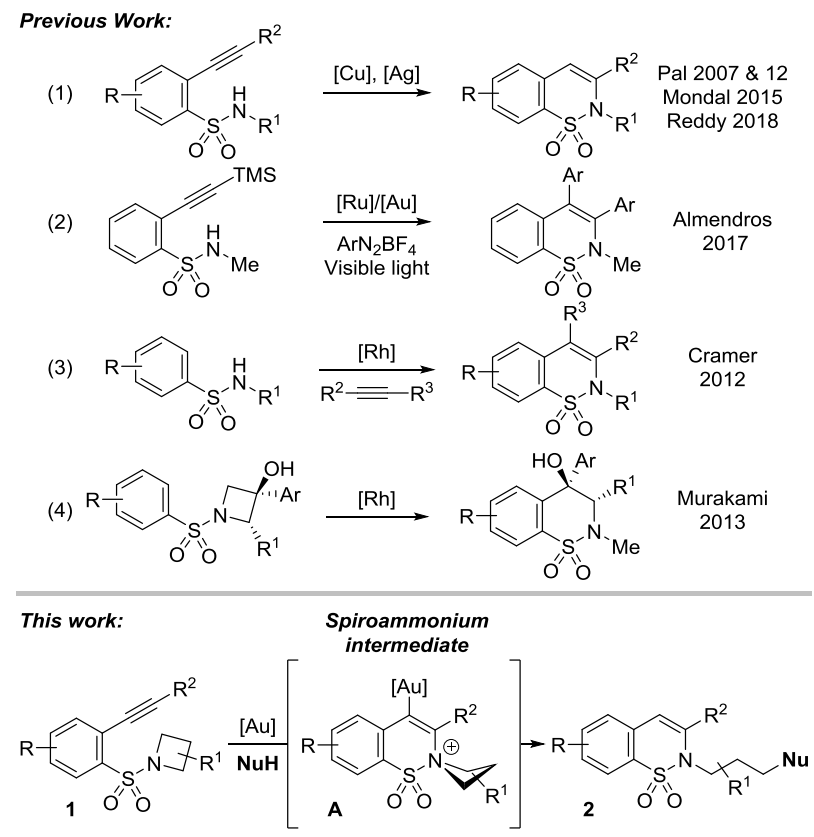

To set up reaction conditions, one of the simplest and easily available $N$-(2-alkynyl)-phenylsulfonyl azetidine, ${ }^{15}$ compound 1a, was prepared from tosylsulfonamide in 3 steps (See Supporting Information) and submitted to different gold complexes as catalysts. Methanol was used as external nucleophile in the presence of dichloromethane as a non-coordinating solvent. Rewardingly, room temperature proved sufficient to promote the expected cascade with the right catalysts, providing the expected benzosultam 2a in high yield (Table 1).

Electron-poor phosphite complex was totally ineffective (entry 1). In contrast, an electron-rich NHC complex allowed some conversion within $8 \mathrm{~h}$, and the expected product was obtained in modest yield (entry 2). Interestingly, the Gagosz catalyst proved to be slightly more effective, providing similar yield of the expected product within $8 \mathrm{~h}$ (entry 3 vs 2). Adjusting the phosphine ligand properties revealed that Buchwaldtype ligand greatly improved chemical yield (80\%, entry 4 vs 3 ). Further tuning of the gold complex counter-ion increased efficiency, while reducing reaction times. Among them, the most effective catalyst was obtained with the less coordinating hexafluoroantimonate anion (entry 5). The use of other poorly coordinating anions such as triflate or tetrafluoroborate led to minor degradation products (entries 6-7 vs 5). Knowing that hydrogen bonding plays an important role in the pre-activation of protic nucleophile, ${ }^{16}$ the overactivity of theses anions can be attributed to their higher hydrogen bond basicity. ${ }^{17}$ Without any catalyst or any nucleophile, or with $5 \mathrm{~mol}^{\%}$ of $\mathrm{HSbF}_{6}$ no transformation was observed (entries 8, 9 and 10).
Table 1. Screening of gold catalysts for the rearrangement of $\mathbf{1 a}$ in the presence of methanol. ${ }^{a}$

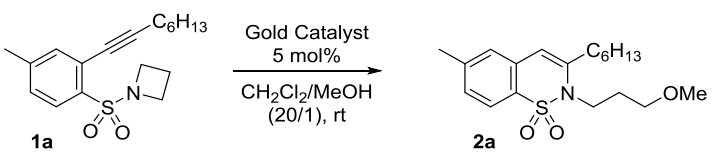

\begin{tabular}{|c|c|c|c|}
\hline entry & catalyst ( $5 \mathrm{~mol} \%$ ) & time $(\mathrm{h})$ & $\operatorname{yield}^{b}(\%) \mathbf{2 a}$ \\
\hline 1 & $(\mathrm{RO})_{3} \mathrm{PAu}(\mathrm{MeCN}) \mathrm{SbF}_{6}{ }^{c}$ & 24 & $-{ }^{d}$ \\
\hline 2 & $\mathrm{IPrAuNTf}_{2}$ & 8 & 30 \\
\hline 3 & $\mathrm{Ph}_{3} \mathrm{PAuNTf}_{2}$ & 8 & 37 \\
\hline 4 & CyJohnPhosAuNTf $_{2}$ & 8 & 80 \\
\hline 5 & CyJohnPhosAu(MeCN)SbF 6 & 1 & 94 \\
\hline 6 & CyJohnPhosAuCl/AgBF 4 & 1 & 78 \\
\hline 7 & CyJohnPhosAuCl/AgOTf & 1 & 90 \\
\hline 8 & - & 24 & $-d$ \\
\hline 9 & CyJohnPhosAu(MeCN)SbF 6 & 24 & $-{ }_{-}, e$ \\
\hline 10 & $\mathrm{HSbF}_{6}$ & 24 & $-^{d}$ \\
\hline
\end{tabular}

${ }^{a} \mathrm{c}=0.1 \mathrm{~mol} / \mathrm{L} .{ }^{b}$ Calculated yield from ${ }^{1} \mathrm{H}$ NMR integration relative to an internal standard (dimethyl terephthalate). ${ }^{c} \mathrm{P}(\mathrm{OR})_{3}=$ tris(2,4-di-tert-butylphenyl)phosphite. ${ }^{d}$ No conversion. ${ }^{e}$ Reaction run without methanol. $\mathrm{Tf}=$ Triflate.

With a catalyst and conditions in hand (Table 1, entry 5), we explored the possibility offered by the present gold-catalyzed transformation.

Scheme 2. Screening of nucleophiles in the rearrangement of 1a into benzosultams $2 .^{a}$

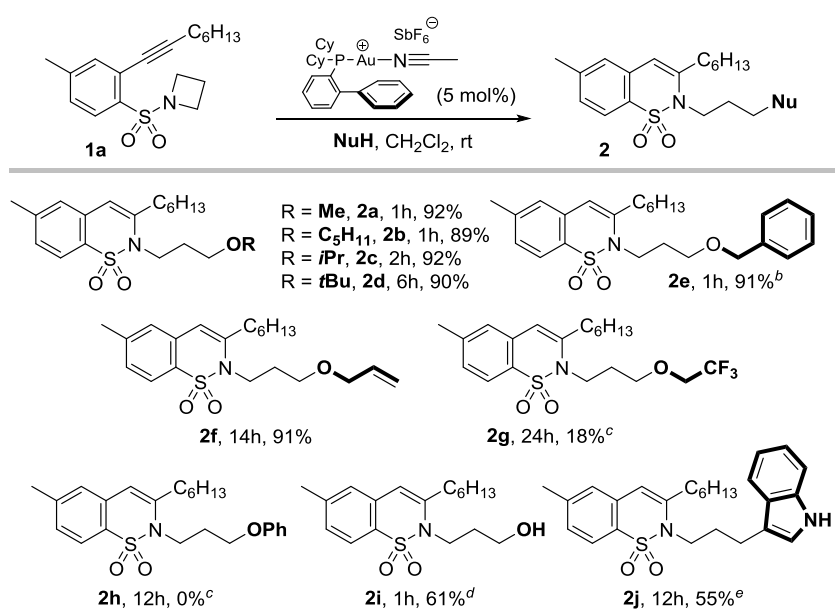

${ }^{a}$ Reaction run with 10 equiv of nucleophiles, $\mathrm{c}=0.1 \mathrm{~mol} / \mathrm{L} .{ }^{b}$ Reaction performed with 1.6 equiv of benzylic alcohol. ${ }^{c}$ Reaction performed at $70{ }^{\circ} \mathrm{C}$ in DCE. ${ }^{d}$ Reaction performed with $\mathrm{CyJ}$ ohnPhos $\mathrm{AuCl}$ and hydrated sample of $\mathrm{AgSbF}_{6}$ as source of water and activator. ${ }^{e}$ Reaction performed at $70{ }^{\circ} \mathrm{C}$ with 3 equiv of indoles.

Various nucleophiles were first applied to this cascade (Scheme 2). Alkyl alcohols provided the expected products (2a-f) in high yields ( 90\%), whatever their size and hindrance. Reaction with tert-butanol was nevertheless slower and required $6 \mathrm{~h}$ instead of $1 \mathrm{~h}$ (see 2d). Benzylic and allylic alcohols reacted as well, although allyl alcohol also required 
longer reaction time (2f vs $\mathbf{2 e}$ ). For comparison, the less nucleophilic trifluoroethanol and phenol were evaluated. The latter was unable to induce the expected cascade, while the former could but after heating and a long reaction time (see $\mathbf{2 g}$ ). These results clearly reflect the nucleophilicity of the alcohol. Although water would be a good nucleophile for this reaction, the expected product could not be obtained by addition of water to the reaction mixture. Rewardingly, water could be introduced by simply using hydrated silver hexafluoroantimonate and $5 \mathrm{~mol} \%$ CyJohnPhosAuCl as precatalyst. Although the reaction time was equivalent to the best nucleophiles, the yield of hydroxysultam $2 \mathbf{i}$ was lower. This result can be assigned to the fact that the formed hydroxysultam plays the role of a competitive nucleophile and leads to a dimerization. ${ }^{14 \mathrm{~b}}$ Other nucleophiles, such as amines or thiols, did not promote any reaction, probably by poisoning the gold catalyst. Nevertheless, indole could act as nucleophile, although it was necessary to raise the reaction temperature up to $70{ }^{\circ} \mathrm{C}$ to get full conversion in a reasonable reaction time and yield of $\mathbf{2} \mathbf{j}$. Indolyl benzosultams was thus available through this straightforward method.

Variation on the three key building blocks of the starting $\mathrm{N}$ (2-alkynyl)phenylsulfonyl azetidine were then introduced in order to evaluate their effect and compatibility with the present gold-catalyzed rearrangement (Scheme 3).

The alkynyl chain could be modified, even with functional group as far as the latter was protected (see $\mathbf{2 k}$ vs $\mathbf{2 a}$, Scheme 2). Nevertheless, the presence of larger group adjacent to the acetylenic moiety imposed the use of some extra equivalent of nucleophile, heating and long reaction time, probably due to some hindrance with the catalyst upon coordination (see $\mathbf{2 m}$ and 2n).

Electronic effects were briefly examined upon varying the substitution on the phenyl moiety. These effects strongly affected the cascade, as revealed by the very slow reaction of the methoxyphenyl derivative 20 compared to the normal behavior of the trifluoromethylphenyl analog $\mathbf{2} \mathbf{p}$.

The azetidine moiety could also be functionalized, as showed by the good reactivity of the hydroxymethylazetidine derivatives $\mathbf{1 h}-\mathbf{i}$, which provided sultams $\mathbf{2 q - \mathbf { r }}$ in high yields within $5 \mathrm{~h}$. It is worth to note that in both cases, in absence of external nucleophile no intramolecular opening by the hydroxy group present on the azetidine moiety took place. For the substrate $\mathbf{1 i}$, the ring-opening of the unsymmetrical azetidinium intermediate (See $\mathbf{A}$, Scheme 1) by methanol led exclusively to sultam $\mathbf{2 r}$. The highly regioselective substitution at the more hindered position could be attributed to hydrogen bonding between the free alcohol of the substrate and the nucleophile (methanol).

Interestingly, terminal alkynes could also be engaged in the present cascade, but with an unexpected reactivity. Under our standard conditions at $70^{\circ} \mathrm{C}$, the product $2 \mathrm{~s}$ was formed together with a new compound 3 starting from 1s. Structural investigations revealed the five-membered sultam and aminal structure of 3. Decreasing temperature, while increasing the catalyst loading and the amount of nucleophile, led selectively after 4 days to aminal 3 in good yield. ${ }^{18}$ Monitoring the reaction by ${ }^{1} \mathrm{H}$ NMR allowed to detect the corresponding fivemembered methylene sultam, which was clearly the intermediate of the aminal 3 (See supporting information). The favored 5-exo-dig pathway at lower temperature is consistent with the known cyclization of terminal alkynes ${ }^{19}$ and with the involvement of a $\sigma, \pi$-digold acetylide complex in the mechanism. $^{20}$

Scheme 3. Synthesis of various benzosultams 2 from $\mathrm{N}$-(2alkynyl)-phenylsulfonyl azetidines $\mathbf{1}$ using methanol as nucleophile. $^{a}$
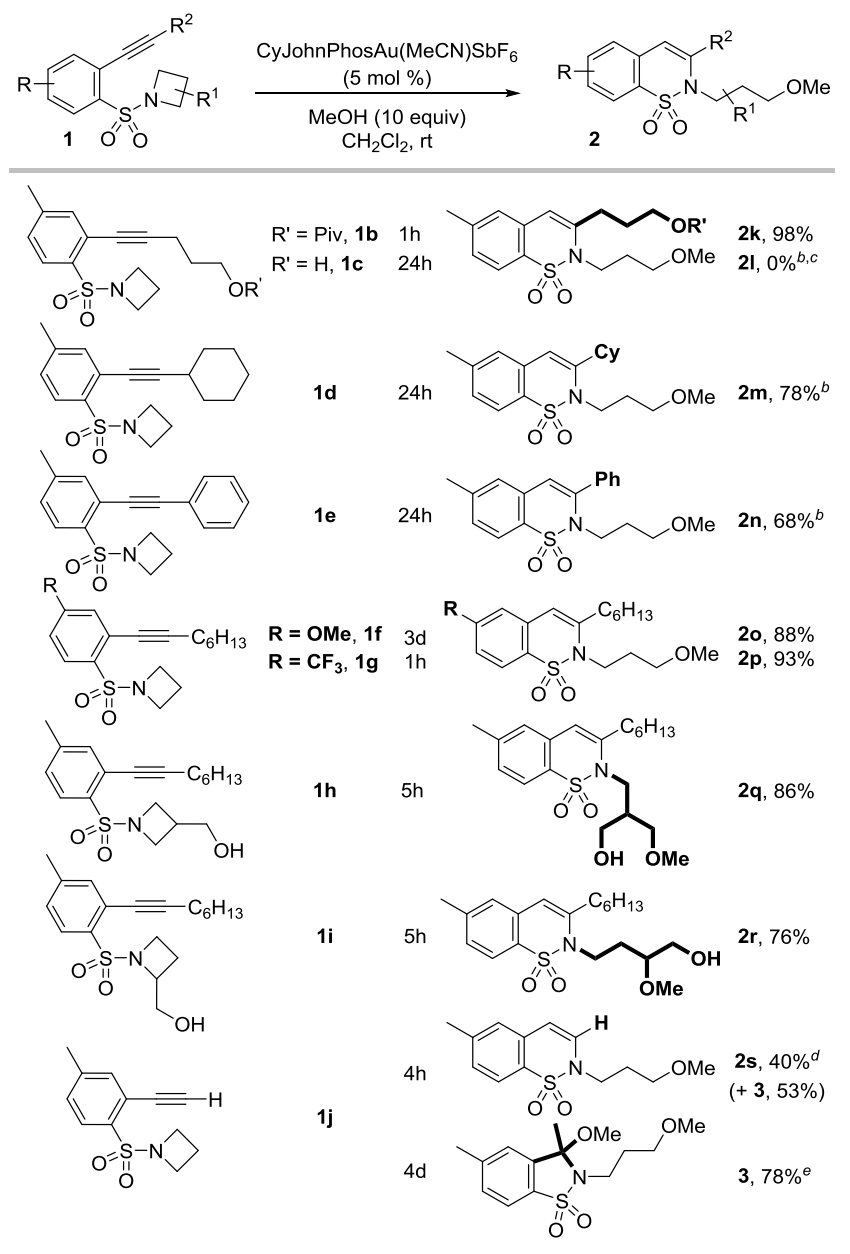

${ }^{a}$ Reaction run with 10 equiv of nucleophiles, $\mathrm{c}=0.1 \mathrm{~mol} / \mathrm{L}$. ${ }^{b}$ Reaction performed at $70{ }^{\circ} \mathrm{C}$ in a DCE/MeOH (1/1) mixture. ${ }^{c} \mathrm{No}$ conversion. ${ }^{d}$ Reaction performed at $70{ }^{\circ} \mathrm{C}$ in a DCE. ${ }^{e}$ Reaction performed at room temperature with $10 \mathrm{~mol} \%$ of catalyst in $\mathrm{CH}_{2} \mathrm{Cl}_{2} / \mathrm{MeOH}(1 / 1)$.

In order to assess the proposed mechanism, a series of blank and trapping experiments were performed (Scheme 4). As mentioned above, no reaction occurred without catalyst (see Table 1 , entry 8 ), and no reaction was also observed without the acetylenic moiety on the substrate $\mathbf{4}$, excluding the azetidine ring-opening through Lewis acid activation ${ }^{21}$ (eq. 1, Scheme 4). Both results highlighted the importance of the acetylenic part and its coordination. In attempts to prove the presence of a vinyl gold intermediate $\mathbf{A}$ after cyclization (Scheme 4, bottom), the reaction in the presence of deuterated methanol as nucleophile was also performed on $\mathbf{1 g}$ (eq. 2, Scheme 4). The formed product $\mathbf{2 t}$ was as expected deuterated at the position where gold should be, according to the proposed mechanism. 
Scheme 4. Blank and isotopic labeling experiments and mechanistic hypothesis.
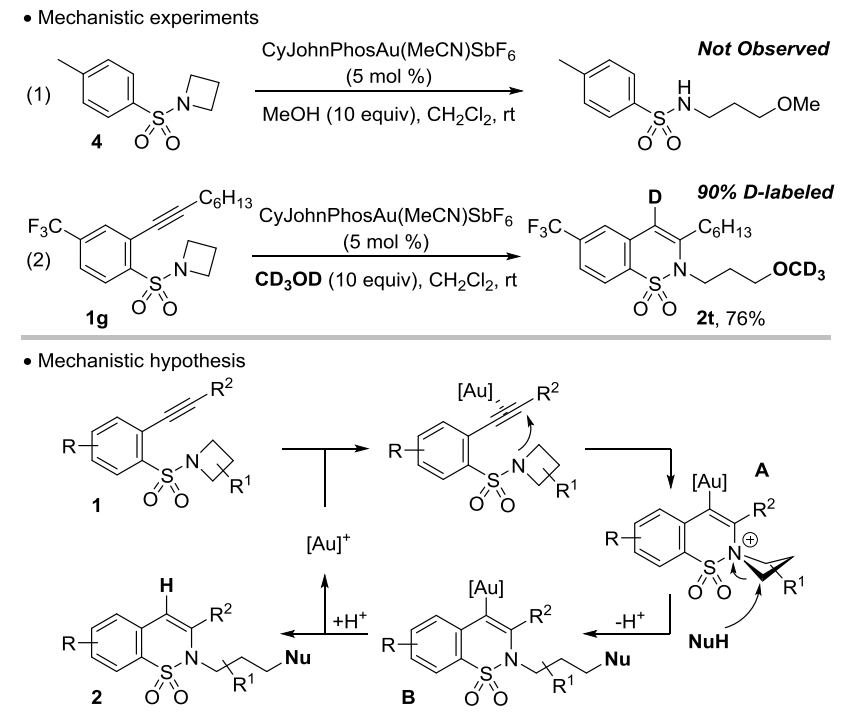

These results strongly supported the formation of a spiroammonium intermediate $\mathbf{A}$, upon gold-activation of the acetylenic moiety and cyclization, its opening with a protic nucleophile, which induced the product formation and the catalyst regeneration by protodeauration (Scheme 4, bottom).

Trapping the organogold intermediate $\mathbf{B}$ with $\mathrm{N}$ iodosuccinimide (NIS) produced useful vinyl iodide derivatives 2u-v in good to excellent yields (Scheme 5), which can be subsequently engaged in cross-coupling reactions. In order to highlight this aspect, one of the products obtained ( $2 \mathbf{v})$ upon NIS trapping was submitted to an arylboronic acid under standard Suzuki-Miyaura reaction conditions. ${ }^{22}$ The coupling product $\mathbf{2 w}$ was easily obtained in good yield (Scheme 5). This possibility expands the pertinence of the gold-catalyzed cascade towards the facile synthesis of highly substituted and functionalized (benzo)sultams. ${ }^{4}$

Scheme 5. Gold-catalyzed formation of 4-iodobenzosultams $\mathbf{2 u}-\mathbf{v}$ in the presence of $N$-iodosuccinimide (NIS) and post functionalization of $\mathbf{2 v}$ by Suzuki-Miyaura cross-coupling reaction.

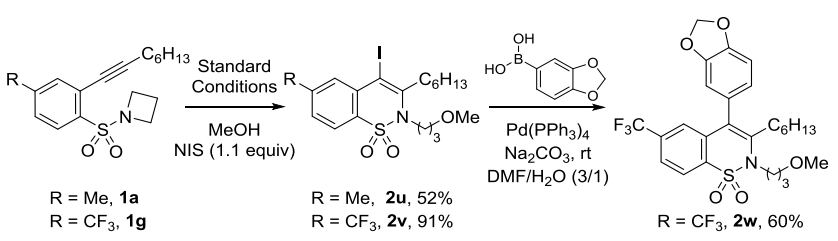

In conclusion, we have described an efficient access to benzosultam derivatives from easily available $\mathrm{N}$-(2alkynyl)phenylsulfonyl azetidines in the presence of nucleophilic alcohols or indoles. This transformation involves an ammonium formation promoted by gold(I) catalysts and the subsequent ring-opening of the so-formed spiroammonium intermediate by external nucleophiles. The importance of the benzosultam motif in medical chemistry as well as the high modularity of this synthetic method provide an attractive tool for the straightforward design of analogs.

\section{ASSOCIATED CONTENT}

\section{Supporting Information}

The Supporting Information is available free of charge on the ACS Publications website.

Experimental details and copies of spectra (PDF)

\section{AUTHOR INFORMATION}

\section{Corresponding Author}

ablanc@unistra.fr

ORCID

Aurélien Blanc: 0000-0003-4240-3281

\section{Notes}

The authors declare no competing financial interests.

\section{ACKNOWLEDGMENT}

We gratefully acknowledge the French Ministry of Research and the CNRS for financial support. R. P. thanks the French Ministry of Research for $\mathrm{PhD}$ fellowship.

\section{REFERENCES}

(1) (a) Domagk, G. Ein Beitrag zur Chemotherapie der bakteriellen Infektionen, Deutsch. Med. Wschr. 1935, 61, 250. (b) Tréfouël, J.; Tréfouël, T.; Nitti, F.; Bovet, D. Activité du $p$-aminophénylsulfamide sur l'infection streptococcique expérimentale de la souris et du lapin, C. R. Soc. Biol. 1935, 120, 756.

(2) (a) Lazer, E. S.; Miao, C. K.; Cywin, C. L.; Sorcek, R.; Wong, H.-C.; Meng, Z.; Potocki, I.; Hoermann, M.; Snow, R. J.; Tschantz, M. A.; Kelly, T. A.; McNeil, D. W.; Coutts, S. J.; Churchill, L.; Graham, A. G.; David, E.; Grob, P. M.; Engel, W.; Meier, H.; Trummlitz, G. Effect of structural modification of enol-carboxamide-type nonsteroidal antiinflammatory drugs on COX-2/COX-1 selectivity. J. Med. Chem. 1997, 40, 980; (b) Winkle, D. D.; Schaab, K. M. Suzuki reaction of a diarylborinic acid: one-pot preparation and cross-coupling of bis(3,5-dimethylphenyl)borinic acid. Org. Process Res. Dev. 2001, 5, 450; (c) Brooke, E. W.; Davies, S. G.; Mulvaney, A. W.; Okada, M.; Pompeo, F.; Sim, E.; Vickers, R. J.; Westwood, I. M. Synthesis and in vitro evaluation of novel small molecule inhibitors of bacterial arylamine $\mathrm{N}$ acetyltransferases (NATs). Bioorg. Med. Chem. Lett. 2003, 13, 2527; (d) Bihovsky, R.; Tao, M.; Mallamo, J. P.; Wells, G. J., 1,2-Benzothiazine 1,1-dioxide $\alpha$-ketoamide analogues as potent calpain I inhibitors. Bioorg. Med. Chem. Lett. 2004, 14, 1035; (e) Zia-ur-Rehman, M.; Choudary, J. A.; Ahmad, S.; Siddiqui, H. L. Synthesis of potential biologically active 1,2-benzothiazin-3-yl-quinazolin-4(3H)-ones. Chem. Pharm. Bull. 2006, 54, 1175 .

(3) Croxtall, J. D.; Scott, L. J. Brinzolamide/timolol: In openangle glaucoma and ocular hypertension. Drugs \& Aging 2009, 26, 437 .

(4) Jacks, T. E.; Belmont, D. T.; Briggs, C. A.; Horne, N. M.; Kanter, G. D.; Karrick, G. L.; Krikke, J. J.; McCabe, R. J.; Mustakis, J. G.; Nanninga, T. N.; Risedorph, G. S.; Seamans, R. E.; Skeean, R.; Winkle, D. D.; Zennie, T. M. Development of a scalable process for CI-1034, an endothelin antagonist. Org. Process Res. Dev. 2004, 8, 201.

(5) Hawkey, C. J. COX-2 inhibitors. Lancet 1999, 353, 307.

(6) (a) Oppolzer, W. Camphor as a natural source of chirality in asymmetric synthesis. Pure Appl. Chem. 1990, 62, 1241; (b) Davis, F. A.; Chen, B. C. Asymmetric hydroxylation of enolates with $N$-sulfonyloxaziridines. Chem. Rev. 1992, 92, 919.

(7) (a) Majumdar, K. C.; Mondal, S. Recent developments in the synthesis of fused sultams. Chem. Rev. 2011, 111, 7749; (b) Rassadin, V. A.; Grosheva, D. S.; Tomashevskii, A. A.; Sokolov, V. V. Methods of sultam synthesis. Chemistry of 
Heterocyclic Compounds 2013, 49, 39; (c) Debnath, S. Mondal, S. Sultams: recent syntheses and applications. Eur. J. Org. Chem. 2018, 933.

(8) (a) Barange, D. K.; Nishad, T. C.; Swamy, N. K.; Bandameedi, V.; Kumar, D.; Sreekanth, B. R.; Vyas, K.; Pal, M. A remarkable accelerating effect of Ag-salt on intramolecular cyclization of $O$-(1alkynyl)benzenesulfonamides. J. Org. Chem. 2007, 72, 8547; (b) Debnath, S.; Mondal, S. One-pot Sonogashira couplingcyclization toward regioselective synthesis of benzosultams. J. Org. Chem. 2015, 80, 3940.

(9) (a) Rambabu, D.; Murthy, P. V. N. S.; Prasad, K. R. S.; Kandale, A.; Deora, G. S.; Basaveswara Rao, M. V.; Pal, M. $\mathrm{AgNO}_{3}$ mediated $\mathrm{C}-\mathrm{N}$ bond forming reaction: synthesis of 3substituted benzothiazines as potential COX inhibitors. Tetrahedron Lett. 2012, 53, 6577; (b) Maheshwar Rao, B.; Yadav, J. S.; Sridhar, B.; Subba Reddy, B. V. Silver(I)-catalyzed sequential hydroamination and Prins type cyclization for the synthesis of fused benzo- $\delta$-sultams. Org. Biomol. Chem. 2018, 16, 5163.

(10) Alcaide, B.; Almendros, P.; Busto, E.; Herrera, F.; LazaroMilla, C.; Luna, A., Photopromoted entry to benzothiophenes, benzoselenophenes, $3 \mathrm{H}$-indoles, isocoumarins, benzosultams, and (thio)flavones by gold-catalyzed arylative heterocyclization of alkynes. Adv. Synth. Catal. 2017, 359, 2640.

(11) Pham, M. V.; Ye, B.; Cramer, N. Access to sultams by rhodium(III)-catalyzed directed C-H activation. Angew. Chem., Int. Ed. 2012, 51, 10610.

(12) Ishida, N.; Shimamoto, Y.; Yano, T.; Murakami, M. 1,5Rhodium shift in rearrangement of $\mathrm{N}$-arenesulfonylazetidin-3ols into benzosultams. J. Am. Chem. Soc. 2013, 135, 19103.

(13) (a) Gold Catalysis: An Homogeneous Approach, Eds. Toste, F. D.; Michelet, V.; Catalytic Science Series, Vol. 13, Imperial College Press, 2014. (b) Modern Gold Catalyzed Synthesis, Eds Toste, F. D.; Hashmi, A. S. K.; Wiley-VCH, 2012; (c) Stephen, A.; Hashmi, K.; Hutchings, G. J. Gold catalysis. Angew. Chem., Int. Ed. 2006, 45, 7896.

(14) (a) Miaskiewicz, S.; Gaillard, B.; Kern, N.; Weibel, J.-M.; Pale, P.; Blanc, A. Gold(I)-catalyzed $N$-desulfonylative amination versus $N$-to- $O$ 1,5-sulfonyl Migration: a versatile approach to 1-azabicycloalkanes. Angew. Chem., Int. Ed. 2016, 55, 9088; (b) Miaskiewicz, S.; Weibel, J.-M.; Pale, P.; Blanc, A. Gold(I)-catalyzed cyclization/nucleophilic Substitution of 1-(N-sulfonylazetidin-2-yl) ynones into $\mathrm{N}$ sulfonylpyrrolin-4-ones. Org. Lett. 2016, 18, 844; (c) Pertschi, R.; Miaskiewicz, S.; Weibel, J.-M.; Pale, P.; Blanc, A. Gold(I)-catalyzed cascade: synthesis of 2,5-disubstituted pyrroles from $N$-sulfonyl-2-(1-ethoxypropargyl)azetidines through cyclization/nucleophilic substitution/elimination. Synthesis 2017, 49, 4151 .

(15) Alcaide, B.; Almendros, P.; Aragoncillo, C., Highly reactive 4-membered ring nitrogen-containing heterocycles: synthesis and properties. Curr. Opin. Drug Discov. Devel. 2010, 13, 685.

(16) (a) Zhdanko, A.; Maier, M. E., Explanation of counterion effects in gold(I)-catalyzed hydroalkoxylation of alkynes. ACS Catal. 2014, 4, 2770; (b) Trinchillo, M.; Belanzoni, P.; Belpassi, L.; Biasiolo, L.; Busico, V.; D'Amora, A.; D'Amore, L.; Del Zotto, A.; Tarantelli, F.; Tuzi, A.; Zuccaccia, D. Extensive experimental and computational study of counterion effect in the reaction mechanism of NHC-gold(I)-catalyzed alkoxylation of alkynes. Organometallics 2016, 35, 641.

(17) (a) Lu, Z.; Han, J.; Okoromoba, O. E.; Shimizu, N.; Amii, H.; Tormena, C. F.; Hammond, G. B.; Xu, B. Predicting counterion effects using a gold affinity index and a hydrogen bonding basicity index. Org. Lett. 2017, 19, 5848; (b) Schiessl, J.; Schulmeister, J.; Doppiu, A.; Woerner, E.; Rudolph, M.; Karch, R.; Hashmi, A. S. K., An Industrial Perspective on Counter Anions in Gold Catalysis: Underestimated with Respect to "Ligand Effects". Adv. Synth. Catal. 2018 , 360, 2493.

(18) Alcaide, B.; Almendros, P.; Carrascosa, R., Straightforward synthesis of bridged azaoxa skeletons: gold-catalyzed aminoketalization of Garner's aldehyde-derived alkynes. Chem. Eur. J. 2011, 17, 4968.

(19) Hashmi, A. S. K.; Schuster, A. M.; Rominger, F. Gold catalysis: isolation of vinylgold complexes derived from alkynes. Angew. Chem., Int. Ed. 2009, 48, 8247.

(20) (a) Brown, T. J.; Widenhoefer, R. A. Cationic gold(I) $\pi$ complexes of terminal alkynes and their conversion to dinuclear $\sigma, \pi$-acetylide complexes. Organometallics 2011, 30, 6003; (b) Wang, J.; Lv, S.; Chen, H.; Shi, M.; Zhang, J. Isolation and characterization of gem-diaurated species having two $\mathrm{C}$-Au $\sigma$-bonds in gold(I)-activated amidiniumation of alkynes. Dalton Trans. 2016, 45, 17091.

(21) Alcaide, B.; Almendros, P.; Aragoncillo, C.; Salgado, N. R., Novel diethylaluminum chloride promoted reactions of the azetidine ring: efficient and stereocontrolled entry to functionalized olefins, pyrrolidines, and pyrroles. J. Org. Chem. 1999, 64, 9596

(22) Barange, D. K.; Batchu, V. R.; Gorja, D.; Pattabiraman, V. R.; Tatini, L. K.; Babu, J. M.; Pal, M. Regioselective construction of six-membered fused heterocyclic rings via $\mathrm{Pd} / \mathrm{C}$ mediated C-C coupling followed by iodocyclization strategy: a new entry to $2 H$-1,2-benzothiazine-1,1-dioxides. Tetrahedron 2007, 63, 1775. 